\title{
Efficacy and Safety of Fentanyl as An Adjuvant with Bupivacaine and Lignocaine in Supraclavicular Brachial Plexus Block
}

\author{
Sanjida Hasan ${ }^{1 *}$ \\ Ahmed Abu Nasar Chowdhury ${ }^{2}$ \\ Syeda Nafisa Khatoon ${ }^{2}$ \\ Md Harun-OR-Rashid ${ }^{2}$ \\ Md Rezaul Hoque (Tipu) ${ }^{2}$ \\ KM Baki Billah² \\ Kalyan Barua' \\ AKM Shamsul Alam²
}

${ }^{1}$ Department of Anesthesiology

Southern Medical College

Chittagong, Bangladesh.

${ }^{2}$ Department of Anesthesiology

Chittagong Medical College

Chittagong, Bangladesh.
*Correspondence to:

\section{Dr. Sanjida Hasan}

Assistant Professor

Department of Anesthesiology

Southern Medical College

Chittagong, Bangladesh.

Mobile : +8801711802614

Email: sanjidahasanurmee@gmail.com

www.banglajol.info/index.php/CMOSHMCJ

\begin{abstract}
Background: Adding narcotics to local anesthetic is very effective in prolonging the analgesic effects. The aim of this study is to evaluation the efficacy and safety of fentanyl as an adjuvant with bupivacaine-lignocaine in supraclavicular block. Methods: This analytical study was carried out in the department of anesthesiology in Chittagong Medical College Hospital in collaboration with the department of orthopedic surgery over a period of 22 months starting from January 2012 to December 2014. A total 130 adult patients of either sex with American Society of Anesthesiology (ASA) health status I-II were selected for upper limb surgery under supraclavicular brachial plexus block was randomly allocated in to two groups of 65 patients in each. Group- $\mathrm{C}$ was received Distilled water $2 \mathrm{ml}$ and Group-F was received fentanyl $2 \mathrm{ml}(100 \mathrm{~g})$ in $38 \mathrm{ml}$ of bupivacaine and lignocaine with adrenaline (Total volume of $40 \mathrm{ml}$ ). Results: The mean onset of sensory \& motor block was $10.49 \pm 0.75 \mathrm{~min} \& 9.41 \pm 0.76 \mathrm{~min}$ in group $-\mathrm{C}$ and $7.60 \pm 3.711 \mathrm{~min} \& 9.23 \pm 5.114 \mathrm{~min}$ in group-F. The duration of analgesia in group-C was $3.81 \pm 0.88 \mathrm{hrs}$ and in group-F was $8.62 \pm 1.747 \mathrm{hrs}$. Conclusion: There was significantly prolonged duration of analgesia and better onset of sensory and motor block in fentanyl group without any unwanted effects.
\end{abstract}

\section{Key words}

Supraclavicular brachial plexus block; Dexamethasone; Fentanyl; Bupivacaine; Lignocaine; Adjuvant.

\section{INTRODUCTION}

Brachial plexus block appears as a very effective alternative of general one. It has the reputation of providing most complete and reliable anesthesia for upper limb surgery as it performed at the trunk level where the plexus is presented most compactly ${ }^{1}$.

Currently available local anesthetics can provide analgesia for limited period of time. Lignocaine is an effective local anesthetic of amide group, with a rapid onset of action and lasts for 60-90 minutes. It has a tendency to cause vasodilatation and this is normally counteracted by the addition of a vasoconstrictor. Adrenaline is used with lignocaine to delay absorption and prolong the action. Bupivacaine is a local anesthetic of amide group, four times more potent than lignocaine, slower in onset but has a significantly longer duration of action ${ }^{2,3}$. However local anesthetics provide analgesia for not more than 4-8 hrs.

It has been suggested since long, that peripheral nerve possess opioid receptors and this has tempted clinicians to add narcotics to local anesthetics to prolong the analgesic effects of these solutions ${ }^{4}$. The peripheral administration of opioid provides stronger and longer lasting analgesia with a lower dose of opioid without central side effects such as respiratory depression, nausea, vomiting and pruritus ${ }^{5}$. Addition of fentanyl to local anesthetics reported to influence post operative analgesia in a study on brachial plexus block ${ }^{6}$. Singh et al. reported that fentanylbupivacaine improves analgesia in supraclavicular brachial plexus block ${ }^{7}$. 
Considering the fact, the current study was planned to compare the anesthetic and analgesic effects of adding fentanyl to bupivacaine-lignocaine in supraclavicular brachial plexus block for upper limb surgery.

\section{MATERIALS AND METHODS}

All patients of both sexes, age 18-60 years, ASA class-I \& class-II undergoing routine operation schedule for upper limb surgery under supraclavicular brachial plexus block were enrolled in this study. Patients were excluded if they had sepsis at the site of injection, body wt $<50 \mathrm{~kg}$, pregnant women, known hypersensitivity, circulatory instability, diabetes, coagulopathy, history of neurological, renal \& liver diseases, peptic ulcer disease.

Patients were randomly selected by card sampling method into two groups. Sample size was 65 in each group. A box was prepared containing 130 cards (C-card \& D-card in equal numbers). Randomization of the sample was done by asking the patient to draw one card blindly from the box. The patients who drew card marked $\mathrm{F}$ were allocated into group- $\mathrm{F}$ and patients with card marked $\mathrm{C}$ were assigned to group-C (Control). After selecting the patient entry of the name of the patients in the case record form and initial pulse, NIBP (Noninvasive Blood Pressure) RR (Respiratory Rate) Saturated Pluse Oximetry $\left(\mathrm{SPO}_{2}\right)$ were monitored and were recorded as base line value.

Group-C (Control) received distilled water $2 \mathrm{ml}$ and Group-F received fentanyl $2 \mathrm{ml}(100 \mu \mathrm{g})$ in $38 \mathrm{ml}$ of Bupivacaine and Lignocaine with adrenalin.

After block given, Patients pulse, Blood pressure, RR, $\mathrm{SPO}_{2}$ were recorded and then first 30 mins at 10 mins interval then 15 mins interval up to the end of surgery.

The onset of sensory block was assessed in every minute using pin prick method in different areas innervated by radial, ulna, median and musculocutaneous nerve. The onset of motor block was assessed in every minute by modified bromage scale compared to the opposite limb by asking the patient to raise their hand or move their fingers. The time of onset of sensory block (The time elapsed between the injection of local anesthetic drugs and just impaired sensation to pinprick perception i e. grade1 compared to the opposite upper limb). The time of onset of motor block (The time elapsed between the injection of local anesthetic drug and just impaired ability to raise the hand i.e. grade 1 of modified bromage scale, compared to the opposite limb) was noted. Duration of block (Time between onset of sensory anesthesia and patient complaining of pain visual analog scale $>3$ ) and quality of block by Numeric scale was noted.

Any incidence of nausea, vomiting, pruritus, respiratory distress, dryness of mouth, local anesthetic toxicity, Pneumothorax, hematoma formation or any others was noted by yes/no. If respiratory distress develops, phrenic nerve block and Pneumothorax were excluded by X-ray chest posterior anterior view. If any side effects detected clinically in per and post operative period then it was managed according to the need. The patient who needed sedative drug assessed by Ramsay Score was recorded.
Postoperative analgesia was noted by interviewing the patient according to Visual Analog Scale (VAS) and Verbal Rating Scale (VRS) in post operative ward.

The sociodemographic variables studied were age, sex and weight. The preoperative variables were pulse, blood pressure, $\mathrm{SpO}_{2}$ respiratory rate. The outcome variables were the assessment of sensory and motor block, onset time of sensory and motor block, duration of surgery, duration of anesthesia, adjuvant required, sedation score, $\mathrm{G} / \mathrm{A}$ required, quality of block, side effects monitored as well as per-operative hemodynamic stability by recording pulse, NIBP, $\mathrm{SPO}_{2}$ and RR. Postoperative variables on analgesic demand by VAS and VRS to determine analgesic demand. A structured case record form was developed containing all the variables of interest. Proper permission was taken for this study from the ethical committee of Chittagong Medical College.

Collected data was complied, checked and edited. Data processing and analysis was done with the help of computer using statistical software SPSS (Statistical Package for Social Sciences) version -18 (Chicago, IL, USA). The test statistics used for analysis of data was Student's t-test (For comparison of data presented in quantitative scale-age, sex, wt) Chi-square test (For comparison of data presented in categorical scaleoutcome in both groups). The results were presented in tables and figures. The statistical terms was included in this study are mean, standard deviation, percentage. Statistical significance was set at $\mathrm{p}<0.05$ and confidence interval set at $95 \%$ level.

\section{RESULTS}

Table 1: Onset of sensory and motor block in study patients $(\mathrm{n}=130)$

$\begin{array}{ccc}\begin{array}{c}\text { Group C } \\ (\mathrm{n}=65)\end{array} & \begin{array}{c}\text { Group F } \\ (\mathrm{n}=65)\end{array} & \text { v } \\ \text { Mean }^{ \pm S D} & \text { Mean }^{ \pm S D} & \end{array}$

Onset of

sensory

block (min) $\quad 10.49 \quad 0.75 \quad 7.60 \quad 3.711$

0.000

Onset of

motor

\begin{tabular}{llllll} 
block (min) & 9.41 & 0.76 & 9.23 & 5.114 & 0.774 \\
\hline
\end{tabular}

*(Calculated by $\mathrm{t}$ - test)

Table 2 : Duration of analgesia between the study groups $(\mathrm{n}=130)$

$\begin{array}{ccc}\begin{array}{c}\text { Group C } \\ (\mathrm{n}=65)\end{array} & \begin{array}{c}\text { Group F } \\ (\mathrm{n}=65)\end{array} & \begin{array}{c}\mathrm{p} \\ \text { value* }\end{array} \\ \text { Mean }^{ \pm \text {SD }} & \text { Mean } & \end{array}$

Duration of

analgesia

$\begin{array}{llllll}(\mathrm{hrs}) & 3.81 & 0.88 & 8.62 & 1.747 & 0.000\end{array}$

*(Calculated by t- test) 
Table 3 : Side effects observed in the study patients $(n=130)$

\begin{tabular}{|c|c|c|c|c|c|c|}
\hline \multirow[t]{2}{*}{ Side effects } & \multicolumn{2}{|c|}{$\begin{array}{c}\text { Group C } \\
(n=65)\end{array}$} & \multicolumn{2}{|c|}{$\begin{array}{c}\text { Group F } \\
(n=65)\end{array}$} & \multicolumn{2}{|c|}{ Total } \\
\hline & No. & $\%$ & No. & $\%$ & No. & $\%$ \\
\hline $\begin{array}{l}\text { Hematoma } \\
\text { formation }\end{array}$ & 1 & 1.5 & 1 & 1.5 & 2 & 6.2 \\
\hline Ptosis & 3 & 4.6 & 3 & 4.6 & 6 & \\
\hline None & 61 & 93.8 & 61 & 93.8 & 122 & 93.8 \\
\hline
\end{tabular}

$\mathrm{p}=1.000($ Calculated by Chi square test $)$

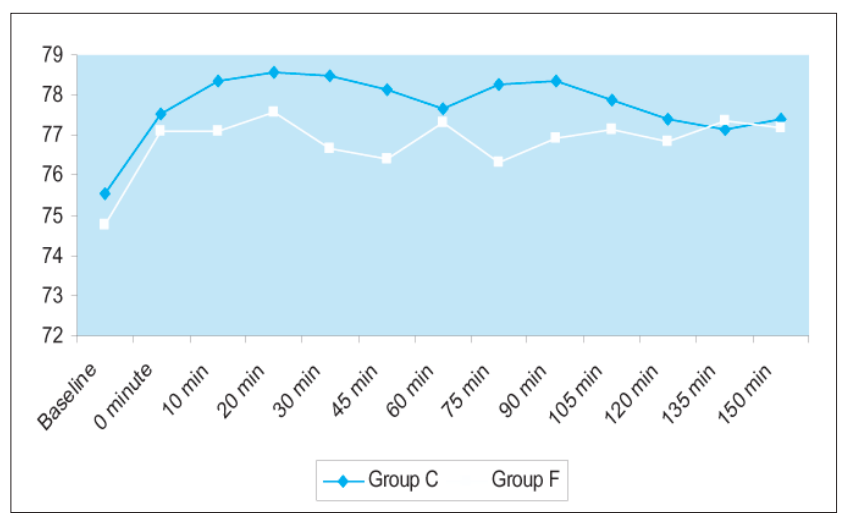

Figure 1: Per operative monitoring of pulse of the study patients $(n=130)$

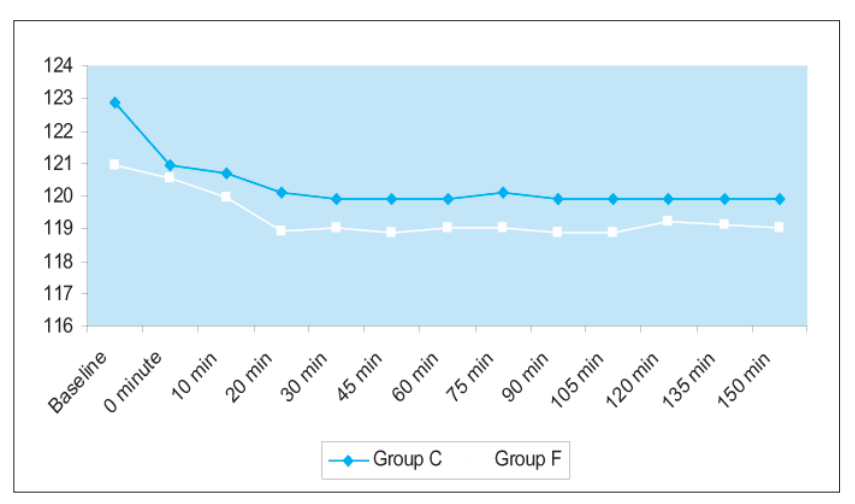

Figure 2 : Per operative monitoring of systolic blood pressure of the study patients $(\mathrm{n}=130)$

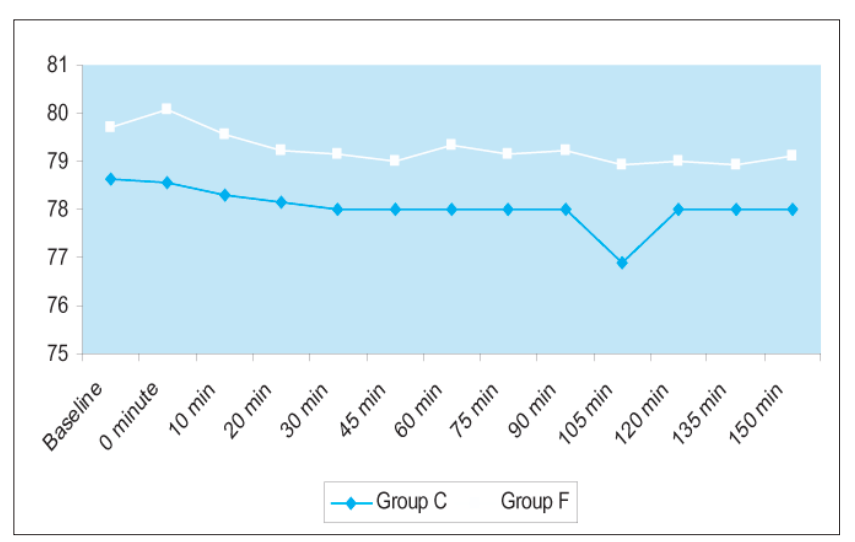

Figure 3 : Per operative monitoring of diastolic blood pressure of the study patients $(\mathrm{n}=130)$
The mean onset of sensory \& motor block was $10.49 \pm 0.75 \&$ $9.41 \pm 0.76 \mathrm{~min}$ in group-C and $7.60 \pm 3.711 \& 9.23 \pm 5.114 \mathrm{~min}$ in group-F. Onset of sensory in two group was statistically significant $(\mathrm{p}=0.000)$ but motor block was not statistically significant $(\mathrm{p}=0.774)$ [Table-1].

The duration of analgesia in group-C was $3.41 \pm 0.88 \mathrm{hrs}$ and in group-F was $8.62 \pm 1.747 \mathrm{hrs}$. The results was significantly higher in group-F than group-C $(\mathrm{p}<0.05)$. [Table-2]

The side effects of procedure and the drug of study patients where 3 case of ptosis, 1 case of hematoma in both groups Total $6.2 \%(\mathrm{p}=1.00)$. [Table-3].

Preoperative variables pluse, $\mathrm{SBP}, \mathrm{DBP}, \mathrm{SPO}_{2}$, resp. rate have no effect on drug group. [Figure 1, 2, 3].

\section{DISCUSSION}

The present analytical study was carried out with the objectives to make a comparative evaluation of the efficacy and safety of fentanyl as an adjuvant with bupivacaine-lignocaine in supraclavicular block during upper limb surgery.

Regarding the mean onset of the sensory block in group- $F$ and group- $\mathrm{C}$ was $7.60 \pm 3.71 \mathrm{~min}$ and $10.49 \pm 0.75 \mathrm{~min}(\mathrm{p}=0.000)$. The mean onset of the motor block in group- $\mathrm{F}$ and group- $\mathrm{C}$ was $9.23 \pm 5.114 \mathrm{~min}$ and $9.41 \pm 0.76 \mathrm{~min}(\mathrm{p}=0.774)$ respectively. Onset of sensory in two groups was statistically significant but motor block was not statistically significant.

As compared to the study done by Sarkar et al where one group received Lignocaine $(2 \%)$ with adrenaline $(1: 2,00,000) 10 \mathrm{ml}+$ bupivacaine $(0.5 \%) 20 \mathrm{ml}+$ distilled water $10 \mathrm{ml}$ and other group received same amount of local anesthetic $+1 \mathrm{ml}(50 \mu \mathrm{g})$ fentanyl, to make total volume of $40 \mathrm{ml}$, in Supraclavicular block using nerve stimulator technique ${ }^{8}$. Onset time of the sensory and motor block was delayed in fentanyl group $4.4 \pm 1.41 \mathrm{~min}$ and $3.04 \pm 1.31 \mathrm{~min}$ respectively than local anesthetic group $(2.88 \mathrm{~min})$. This does not correlate with the present study done by paraesthesia technique. In a study, Ahmed et al, used $100 \mathrm{~g}$ fentanyl in $40 \mathrm{ml}$ of $0.25 \%$ of bupivacaine in the supraclavicular approach in paraesthesia technique and achieved the onset of the sensory and motor block at $8.9 \pm 2.9 \mathrm{~min}$ and $8.8 \pm 2.7 \mathrm{~min}$, respectively ${ }^{9}$. The results nearly matched with the present study. Almost similar result was depicted in a comparative study carried out by Chavan and colleagues, by addition of Fentanyl to local anesthetics (Bupivacaine 0.5\% and Lignocaine 2\%) undergoing surgery of forearm and hand with Supraclavicular approach and revealed that the gripping forces significantly decreased 10 minutes after the injections ${ }^{6}$. The onset of sensory block was faster than motor block in both groups in this study which was similar in most of the study done in brachial plexus block. But the study done by Jarbo et al and Shrestha et al, have shown in their study, the onset time of motor block was significantly faster than the onset of the sensory block, which does not correlate with those found in present study ${ }^{10.11}$. This can be explained by the "core and mantle concept" of Winnie ${ }^{12}$. As described by Winnie, the outer motor fibers are blocked earlier 
than the sensory fibers which are situated deeper in the brachial plexus at the level of trunk and division. But the earlier time to achieve the sensory block than motor in present study, as compared to theirs, can be attributed to the mixture of local anesthetics which were used.

The duration of analgesia in present study was demonstrated in group-C was $3.41 \pm 0.88 \mathrm{hrs}$ and in group-F was $8.62 \pm 1.747 \mathrm{hrs}$. The results was significantly higher in group-F than group-C $(\mathrm{p}<0.05)$.

Regarding the duration of analgesia with fentanyl in brachia plexus block in a study by SP Singh and colleagues, they found the duration was maximum with the addition of fentanyl to local anesthetic $(7.28 \pm 0.55 \mathrm{hrs})$. Similar result was depicted in a comparative study carried out by Chavan and colleagues to evaluate the analgesic efficacy and side effects of addition of fentanyl to local anaesthetics ${ }^{6}$. The study revealed that mean duration of analgesia was extended $(695 \pm 85 \mathrm{~min})$ if fentanyl is added to local anesthetics without increasing the side effects, however onset time of analgesia was prolonged. Both the results nearly matched with the present study. Similarly, there were number of study regarding duration of analgesia, such as in Ahmed et al was $10 \pm 1.5 \mathrm{hrs}$ and Sharker et al was $11 \mathrm{hrs}$, Denz et al was $10.1 \mathrm{hrs}^{9,8,13}$. These results were also nearly matched with this present study.

Regarding the side effects the present study was showing side effects of ptosis was found 3 case and Hematoma in 1 case in both group. All above side effects were related to procedure rather than drug. Others side effects like nausea, vomiting, pruritus, respiratory distress, dryness of mouth, LA toxicity (CNS, CVS, Hypersensitivity) Pneumothorax was not found in both groups. Though the Pneumothorax is possible complication when attempting supraclavicular block. But the incidence of Pneumothorax is likely reduced by operator experience and using shorter needles with caution ${ }^{14,15}$. The side-effects reported after opioids administration in a study done by Bazin et al, was pruritus (1) nausea (2) vomiting (3) ${ }^{16}$. However, such side-effects were relatively rare and their incidence was similar to that reported previously ${ }^{17}$. The serious potential risk of opioid administrations respiratory depression, although it seems a small risk in young patients given the doses of opioids currents used. Moreover, all the side-effects observed in Bazin et al study took place during the first $6 \mathrm{~h}$ following the injection. This suggests that blood level became very low after this time.
In the present study the baseline characteristics were within normal value, which support the Jarbo et al study ${ }^{10}$. In this study it was observed that per-operative mean pulse rate, systolic blood pressure, diastolic blood pressure, $\mathrm{SP}_{2}$ and respiratory rate changes at different times were almost similar between two groups, no significant $(p>0.05)$ mean difference was found. In another study Dogru et al. showed stable hemodynamic parameters in their study groups, which support the present study findings ${ }^{15}$.

\section{LIMITATION AND RECOMMENDATIONS}

It was a single center study. Relative perception of pain by the patients may have caused biasness regarding postoperative pain assessment by VAS and VRS and that could have affected the findings of the present study. Availability of an ultrasound and/or peripheral nerve stimulator would have helped to achieve more accurate nerve blocks.Large scale multicenter double blind study with nationally representative sample and nerve stimulator or ultrasound guided techniques, find more accurate result to have a conclusion.

\section{CONCLUSION}

In this study, main analysis was done on duration of analgesia by use Fentanyl as an adjuvant with Bupivacaine and Lignocaine in Supraclavicular brachial plexus block. In our study Fentanyl group was more prolonged duration of analgesia than Control group. Onset of sensory and motor block and hemodynamic stability was almost similar in both groups.

So, on the basis of student's t-test and Chi-square test, we can conclude that there was significantly prolonged duration of analgesia and better onset of sensory and motor block in Fentanyl group without any unwanted effects.

\section{DISCLOSURE}

All the authors declared no competing interest. 


\section{REFERENCES}

1. Neal JM, Gerancher JC, Hebl JR, IIfield BM et al. Upper Extremity Regional Anesthesia: Reg Anaesth Pain Med.2009; 34(2): 134-170.

2. Neal MJ, Hebl JR, Gerancher JC, Hogan QH. Brachial Plexus Anesthesia: Essentials of Our Current Understanding. Reg Anesth and Pain Med.2002; 27: 402-428.

3. Covino BG, Wildsmith JAW. Clinical pharmacology of local anesthetic agents. In: Cousins MJ, Bridenbaugh PO, eds. Neural blockade in clinical anesthesia and management of pain. Philadelphia: Lippincott-Raven Publishers; 3rd Ed.1998; 97-128.

4. Books JHJ, Gupta B. Further evidence for narcotic receptors in human peripheral nerve. Regional Anesthesia. 1990; 15: 215.

5. Stein C. Peripheral mechanisms of opioid analgesia. Anesth Analg.1 993; 76: 182-191.

6. Chavan SG, Koshire AR, Panbude P. Effect of addition of Fentanyl to local anesthetic in brachial plexus block on duration of analgesia. Anesthesia: Essays and Reaches.2011; 5(1):39-42.

7. Singh SP, Singh V, Kaushal D, Jafa S. Comparison of Fentanyl-Bupivacaine and Alkalinized Bupivacaine in Supraclavicular brachial plexus block: A double blind, randomized controlled trial. Available from: http://www.aja-online.com.pdf. Accessed on 20.6.2011.

8. Sarker D, Khurana G, Chaudhary A, Sharma JP. A comparative study on the effects of adding fentanyl and Bupivacaine to local anaesthetics in brachial plexus block. Journal of clinical and Diagnostic Research.2010; 4:3337-3343.

9. Ahmed NU, Hossain M, Akhtaruzzaman AKM, Mondol MK, Khatun UHS. Addition of clonidine or fentanyl with Bupivacaine for Supraclavicular brachial plexus block in upper limb surgery: A randomized comparative study.Journal of BSA.2011; 24(1).

10. Jarbo K, Bara YK, Panda NB. Brachial plexus block with midazolum and Bupivacaine improves analgesia. Can J Anaesth.2005; 52: 822-826.

11. Shrestha BR, Maharjan SK, Shrestha S, Gautam B, Thapa PB, Joshi MR. 'Comparative study between tramadol and dexamethasone as an admixture to bupivacaine in supraclavicular brachial plexus block', J Nepal Med Assoc.2007; 46(168); 158-164.

12. Winnie AP, Tay CH, Patel KP, Ramamurthy S.Durrani z. Pharmacokinetics of local anaesthesia during plexus block. Anaesth Analg.1977; 56: 852-861.

13. Deniz K, Fazl B, Sibel B, Fuat G, Ayla T. Addition of Fentanyl to Bupivacaine prolongs anesthesia and analgesia in axillary brachial plexus block. Reg Anesth Pain Med.2001; 26: 434-438.

14. Moore DC, Bridenbaugh LD. Pneumothorax. Its incidence following brachial plexus block analgesia. Anesthesiology. 1954; 15: 475-479

15. Harley N, Gjessing J. A critical assessment of Supraclavicular brachial plexus block. Anesthesia. 1969; 24: 564-570.

16. Bazin BZ, Massoni C, Bruelle P, Fenies V, Groslier D, Schoeffler P. The addition of opioids to local anesthetic in brachial plexus block: the comparative effects of morphine, buprenorphine and suefentanil. Anaesthesia. 1997; 52: 858-862.

17. Gobeaux D, Landais A, Bexon G. Addition of fentanyl to adrenalized lidocaine for the brachial plexus block. Anesthesiology. 1987; 35: 195199.

18. Dogru K, Duygulu F, Yildiz K, Kotanoglu MS, Madenoglu H, Boyaci A, 'Hemodynamic and blockade effect of high/low epinephrine dose during axillary brachial plexus blockade with lidocaine 1.5\%: A randomized, double blinded study', Anesth Pain Med.2003; 28(5): 401-405. 